\title{
Adapted customer relationship management implementation framework:facilitating value creation in nursing homes
}

Article

Accepted Version

Gulliver, S. R., Joshi, U. B. and Michell, V. (2013) Adapted customer relationship management implementation framework:facilitating value creation in nursing homes. Total Quality Management and Business Excellence, 24 (9-10). pp. 991-1003. ISSN 1478-3371 doi:

https://doi.org/10.1080/14783363.2013.776771 Available at https://centaur.reading.ac.uk/31604/

It is advisable to refer to the publisher's version if you intend to cite from the work. See Guidance on citing.

To link to this article DOI: http://dx.doi.org/10.1080/14783363.2013.776771

Publisher: Taylor \& Francis

All outputs in CentAUR are protected by Intellectual Property Rights law, including copyright law. Copyright and IPR is retained by the creators or other copyright holders. Terms and conditions for use of this material are defined in the End User Agreement. 


\section{www.reading.ac.uk/centaur}

\section{CentAUR}

Central Archive at the University of Reading

Reading's research outputs online 


\title{
Adapted Customer Relationship Management Implementation Framework: Facilitating Value Creation in Nursing Homes
}

\begin{abstract}
This paper proposes a framework to support Customer Relationship Management (CRM) implementation in nursing homes. The work extends research by Cheng et al. (2005) who conducted in-depth questionnaires to identify critical features (termed value-characteristics), which are areas identified as adding the most value if implemented. Although Cheng et al. did proposed an implementation framework, summary of, and inconsistent inclusion of valuecharacteristics, limits the practical use of this contribution during implementation. In this paper we adapt the original framework to correct perceived deficiencies. We link the value characteristics to operational, analytical, strategic and/or collaborative CRM solution types, to allow consideration in context of practical implementation solutions. The outcome of this paper shows that, practically, a 'one solution meets all characteristic' approach to CRM implementation within nursing homes is inappropriate. Our framework, however, supports implementers in identifying how value can be gained when implementing a specific CRM solution within nursing homes; which subsequently support project management and expectation management.
\end{abstract}

\section{Keywords}

CRM, Implementation, Framework, Nursing Home, Value-Characteristics

\section{Introduction}


Around the world, the 85 -and-over population is projected to increase $151 \%$ between 2005 and 2030 , compared to a $104 \%$ increase for the population age 65 and over and a $21 \%$ increase for the population under age 65 (Cook and Halsall, 2012). In the UK, the number of people aged over 65 increased from 8.4 million people in 1981 to 10.2 million people in 2011; causing a shift in the median age from 35.4 years to 39.7. Between 2010 and 2035 the median age is predicted to rise to 42.2 years (ONS, 2012). Hancock et al. (2003) stated that the projected number of people in the UK aged 85 and older would also increase by over two million in the next fifty years. There is, therefore, a growing need for appropriate care provision for the elderly. This problem is compounded for local authorities by a limited amount of resources (Bathurst, 2011). Dahlgaard, Pettersen, and Dahlgaard-Park (2011) suggest that three aims of healthcare are: providing care, enhancing health, and maintaining low costs; however the question of what care people need, and how can this be provided with ever reducing resources, still remains. There are various levels of care, i.e. home care, carehomes, nursing home and hospitalised care, yet what decides the level of care that is provided to the individual? Is it cost? Is it physical demand (i.e. whether the elderly person physically be at home)? The level of care needed? Or is it level of resistance (i.e. if the individual doesn't want to leave their own home)?

Local Authorities in the UK are responsible for the allocation of financial resources with regards to care spending, and with the reduction in spending proposed by the UK government, current insufficient services are going to be further reduced (Altmann, 2011). Age UK (2011) found that 61 out of the 139 councils surveyed are creating savings by increasing or producing new charges on social care provision including home help or day care centres, which are paid for by the individual. Since individuals and/or families are being asked to pay top-up fees, a trend is emerging of customer empowerment (Ouschan et al., 2006). Interestingly MacStravic (2000) found that, if managed, patient empowerment could aid healthcare organisations more than consumers; since patients are often happy to spend their own money to gain additional or customised treatment; supporting the argument that a customer-centric philosophy is essential to the development of new innovative products and services through by identification of customer problems and needs (Dahlgaard-Park \& Dahlgaard, 2010). Michie et al. (2003) showed that empowering the patient-physician interaction leads to a more positive health outcome, and is view held by globally many as a chance to lower excess healthcare costs and optimise healthcare outcomes (Vemarec, 1999). 
To manage empowerment, and to allow residents' medical and personal needs to be identified (Berglund, 2007), we suggest the adoption of CRM (Customer Relationship Management).

CRM is a strategic dialogue with customers, through a customised delivery of a service or product, to ensure that each customers contribute to the maximised profitability of the organisation (Bohling et al., 2006). CRM implementation is often perceived as strategic, yet it is fast becoming a survival tool in heavily user-centric domains (Chang, 2007). By capturing the correct information about residents to support service provision, CRM can be used to create value for patients by supporting trust creation (Oinas-Kukkonen, Raisanen, \& Hummastenniemi, 2008), and the building of long-term relationships (Sun, 2001). CRM management of care provision can deliver a empowered customised service, which swiftly meets current and/or potential patient needs, enhances healthcare service quality, allows increased valued added, increases patient satisfaction and increases mutual benefit (Cheng et al., 2005). Moreover CRM facilitates healthcare providers with a method to gain more information about residents in order to support development of appropriate care adjustments (Benz and Paddison, 2004). Literature offers generic CRM models (Riyad, 2007), as well as specific consideration of CRM implementation in nursing homes and healthcare (Cheng et al., 2005; Glaser and Foley, 2008), yet despite discussion of how customer relationship can be effectively mapped to operational activity (e.g. Schniederjans et al, 2011; Chahal, 2010; Vargo \& Lusch, 2008), literature rarely considers the practical mapping to solution type.

In section 2 we introduce the reader to the domain of CRM, describing how CRM solutions fall across four distinct categories of CRM solutions, i.e. operational, collaborative, analytical and strategic. In section 3 we introduce the Cheng et al. (2005) healthcare framework, and introducing the need for case, data and care management. In section 4, we critically discuss the shortcomings in the Cheng et al. (2005) framework, and argue that adaptation is required to create a framework that allows key value characteristics to be identified. Moreover, in section 4 we propose an adapted framework to support identification of value characteristics, and support implementation alignment with the four defined CRM solution categories. In section 5 we provide a summary of the work and highlight our research contributions.

\section{Introducing Customer Relationship Management}


There are multiple definitions of Customer Relationship Management (CRM) in literature. CRM is the amalgamation of a business strategy and an IT strategy (Payne and Frow, 2005), and includes dimensions relating to business strategy (Gummesson, 2002), customer lifecycle management (Galbreath and Rogers, 1999; Nancarrow et al., 2003), information technology (Shoemaker, 2001) and communication (Swift, 2001). Buttle (2004) defines CRM as the main business strategy that combines internal processes and functions, and external networks, to generate and provide value to the targeted customers with the goal of obtaining a profit; yet describes it as being grounded on high value customer-related data and facilitated by information technology.

Using CRM technologies, care providers can develop a one-to-one relationship (Peppers and Rogers, 1993), formulate added value (Barnes, 2001; Storbacka and Lehtinen, 2001), control cost and spending (Johnson and Nunes, 2003) and/or analyse customer value (Nykamp, 2001). Payne and Frow (2005) examined the value creation process and found that business and customer strategy evaluations can be transformed into implementable programmes, which create value for both the customer and the organisation.

Interestingly, METAGroup (2001) stated that there are three different types of CRM solutions, i.e. operational, collaborative and analytical; however Lin and Su (2003) and Buttle (2009) distinguish strategic CRM as being seperate. Operational CRM relates to appropriate and reproducible business processes created to execute the firm's preferred customer relationship model in the areas of customer access, customer interaction, sales and channel choices and customer learning on an individual basis (Tanner et al., 2005). Collaborative CRM employs a combination of collaborative services and infrastructure to ensure that an interaction between a company and its multiple channels can be achieved (Payne, 2006). Analytical CRM relates to acquiring, warehousing, isolating, combining, managing, understanding, disseminating, employing and conveying customer-related data to enhance both customer and company value (Buttle, 2009). Strategic CRM relates to the continued establishing and provision of value to customers (Plakoyiannaki and Tzokas, 2002). Lin and $\mathrm{Su}$ (2003) state that strategic CRM provides the chance to influence customer knowledge and produce value for customers, therefore aiding organisations in understanding and satisfying customers' needs. 


\section{Healthcare CRM Framework}

The medical care industry is a service industry that is fundamentally dependent on the creation of relationships (Cheng et al., 2005). To support this relationship Cheng et al. (2005) proposed a CRM framework (seen Figure 1) for specific use in the nursing home domain. The CRM framework created by Cheng et al. (2005) was influenced by Rigby et al. (2002) and Campbell (2003).

Cheng et al. (2005) focused on CRM implementation in nursing homes in Taiwan, which is also suffering from an ageing population. They suggested that CRM in nursing homes should contain three aspects: i) case management customer relationships; ii) information management customer relationships; iii) care management customer relationships.

\section{FIGURE 1 HERE}

\section{Customer Relationship - Case Management}

An interactive mechanism offers patients, who require long-term care services, a means of obtaining a personalised plan of services. The interactive mechanism integrates varied service channels, including face-to-face services, facsimile, e-mail, long-term care related websites, discharge planning units of nursing homes and hospitals, in order to supply patients and families with a reliable contact centre so to ensure delivery of a timely, dependable, precise and high quality service channel.

Within the case management process, interactive communication between healthcare workers and customers is significantly important to ensure the need vs service delivery gap is minimised. Healthcare workers should take part in a learning relationship with both patients and their families in the 'assessment of demand model', i.e. to recognise their needs and to create care plans that would serve as a reference for individualised care packages.

\section{Customer Relationship - Data Management}

The healthcare industry is knowledge intensive and therefore healthcare institutions (i.e. nursing homes) have a growing need for customer knowledge management (Bose, 2003). 
Knowledge is based on data, which should, therefore, be organised and managed (Bender and Fish, 2000). Knowledge management (KM) comprises of processes that enable the use and development of organisational knowledge; so as to generate value and to enhance and maintain competitive advantage (Carlucci et al., 2004). Therefore, knowledge management signifies a fundamental element of CRM, and has been used within the framework proposed by Cheng et al. (2005) to identify the needs of the residents so a personalised care plan can be created. Effective use of knowledge management, and a knowledge database, is often necessary to successfully gather, amass, relocate and analyse the vast quantities of data being produced. This amount of data, however, holds considerable useful knowledge that can be applied to service provision development.

CRM provides a customised and individualised service strategy to meet individual customer demands. From the analysis of data, collected within case management, we can identify resident characteristics, which can be used to segment care. 'Suggested solutions' involves proposing solutions that assist healthcare workers in the nursing home to gain an advanced understanding of patient's needs and promote a service relationship between the nursing home and the patient, which meets their needs and forms the basis of an individualised service plan.

\section{Customer Relationship - Care Management}

With the employment of IT, and due to use of analytical tools to segment residents with different backgrounds and needs, numerous care service strategies can be generated. As a result, through 'care design' can be managed, with a comprehensive care plan and customised services; which can be integrated with case management. The care plan should aim to fulfil the care demands of each resident, should provide a long-term interactive channel plan for residents and their families, and should aim to enhance service and supervising care quality. After the service is implemented by the nursing home, applicable data has to be entered into the database, and the physical and mental condition of each resident, and their care demands, should be assessed on a daily basis via 'care delivery' by nursing home staff.

With regards to CRM 'monitoring and feedback', the work of Cheng et al. (2005) relates 
mostly to ensuring that internal and external stakeholders understand their responsibilities and responses to care delivery.

It is clear in Cheng et al. (2005) that Nursing homes mostly do not know how to conduct a CRM implementation, or what value characteristics would be useful to consider implementing to capture the right information for use in service provision. Accordingly it is essential that nursing-home CRM implementation prioritises the solution implementation around CRM value characteristics.

\section{Creating a characteristic-based framework for Implementation of CRM in Nursing Homes}

\subsection{Questionnaire Analysis of CRM in Nursing Homes}

To understand where CRM can most effectively add value within the nursing home domain, Cheng et al. (2005) analyzed international CRM and nursing-home-related documentation; thus determining the essential characteristic elements that defined the nursing home domain. This is critically important, because despite validation in Taiwan, the characteristic elements can be applied internationally. Questionnaires were created to capture feedback concerning 84 characteristic elements. For each characteristic two pieces of information was captured: user feedback concerning perceived level of importance, which was captured using a fivepoint Likert scale, with five to one representing respectively 'very important', 'important', 'normal', 'not important', and 'very unimportant'; and level of current execution, defining characteristics that nursing homes perceive that they are already doing, with information captured on a five-point Likert scale, with five to one representing respectively 'completely achieved', 'mostly achieved', 'normal achievement level', 'largely unachieved', and 'not achieved at all'.

225 questionnaires were distributed amongst managers or nursing supervisors at 211 nursing homes. 107 questionnaires that were returned; however 14 were deemed invalid. Cronbach's reliability was used to establish internal consistency of the rating scale in each

different assessment dimension; categorised by component parts of the CRM Framework (see figure 1). A computed alpha coefficient ranges between 1 (representing perfect internal reliability) and 0 (representing no internal reliability); with 0.8 used to represent an adequate 
level of internal reliability. As all of the reliabilities exceeded 0.8 , the reliability of data was seen as being high, i.e. all dimensions of the questionnaire are dependable and constant. Due to the Likert scale definition, a mean score greater than four was categorised as being either important and/or very important; and was therefore deemed as critical. The three dimensions that obtained the greatest importance were: 'Behaviour of service personnel (4.76)', 'Design of care processes (4.62)', and 'support from the related units (4.61)'. CRM characteristics that where most executed in nursing homes were: 'Customer data collection (4.21)', 'Behaviour of service personnel (4.21)', and 'Design of care process (4.15)'. According to the results, the three areas where practitioners consider themselves as having underachieved were: Data analysis (3.23), Care service strategy (3.64), and Knowledge management (3.70). Interestingly the results relate closely to the level of computerisation used at specific individual nursing homes, the information system equipment available, and recognition by management of CRM.

\subsection{Directions for Improving Nursing Home Quality Care}

Cheng et al. (1998) established that when the quality expectancy of two challenging items, or the difference between expectation and satisfaction, is equal, the quality of the two challenging items should demonstrate a rule that can decide the value prioritisation. The characteristics used in this study to evaluate the significance of CRM are calculated using the following formula:

$I V_{C i}($ Importance Value, Corrected $)=($ Importance-Current status $) \times \operatorname{Importance}=\left(\mathrm{I}_{\mathrm{i}}-\mathrm{N}_{\mathrm{i}}\right) \times \mathrm{I}_{\mathrm{i}}$

$\mathrm{li}$ is the importance of characteristic $\mathrm{i}$. Ni is the current execution status of characteric $\mathrm{i}$. Both $\mathrm{i}$ and $\mathrm{Ni}$ are determined from questionnaire Likert scales.

$\mathrm{li}-\mathrm{Ni}<0 \quad$ Current activity is perceived as being well appropriate in context of importance.

$\mathrm{li}-\mathrm{Ni}=0 \quad$ Current activity is perceived as appropriate in context of importance.

$\mathrm{li}-\mathrm{Ni}>0$ Current activity is not appropriate in context of importance. Therefore, the root cause must be located to make relevant improvement plans.

Following the identification of the $\mathrm{IV}_{\mathrm{Ci}}$ value for each characteristic, Cheng et al. (2005) used a $80 / 20$ principle to categorise characteristic importance into five categories, i.e. absolutely important, very important, quite important, important and normal. They argued that by using 
this method, nursing homes have a more comprehensive understanding of the value potential of each CRM characteristic. Accordingly Cheng et al. (2005) identified the 17 top CRM value characteristics that best support value creation with in nursing homes.

\subsection{Classification of Characteristics}

Three characteristics were identified relating to Case Management: i) the nursing home needs a method to manage the interaction of residents and their families; ii) the nursing home should repeatedly interact with the community residents to create good interactions; and iii) the residents should be assessed by a professional within a time scale of seven days from them arriving at the institute to allow carers to appreciation needs and customisation of care.

Six characteristics relating to Data Management: i) the nursing home should create its own long-term care website to allow customers to gain pertinent information in a straightforward manner and enhance customer interactions; ii) the nursing home should distinguish target customers in accordance with the types of residents in the database and run one to one communications with residents and their family members in order to meet their needs; iii) the nursing home should alter its marketing strategy given the results received from data analysis; iv) staff should analyse and forecast the requirements of distinct residents and their family members utilising IT analysis; v) homes should generate individualised care plans, which are constructed using the results of the data analysis; vi) the nursing home should encourage staff to be imaginative in planning care to satisfy resident needs.

Eight characteristics were identified as relating to Care Management: i) The home should intermittently evaluate staff satisfaction; ii) The home should implement unit care, with around ten people per living unit. Each unit consists of a living room, kitchen and dining room; iii) The should consider requests consider obtaining help from consulting firms to administer activities connected with enhancing customer relationships; iv) The home should employ surveillance in public areas to manage resident activities; v) The home should actively search for new residents; vi) The nursing home should deliver various alternative treatment options; vii) The nursing home should enthusiastically employ and get in contact with volunteers, social organisations or school organisation to assist in establishing activities; and viii) Each staff member should partake in both activities connected with enhancing customer relationships, and boosting their job satisfaction.

\subsection{Critical Review of Results}

Cheng et al.'s proposed framework for introducing CRM implementation in nursing homes 
(see figure) is based on the results that they obtained from the value characteristic questionnaire. The framework, however, groups characteristics, to support an understanding of relevant themes; yet a

seems inappropriate in context of a CRM implementation. In 'Case Management', for example, themes 'interactive mechanism' and 'assessment of demand model' do not clearly map to the three characteristics defined by questionnaire result. Since multiple implementation methodologies, and/or CRM solutions could be used to implement characteristic, it would seem more appropriate consider all characteristics separately.

\section{FIGURE 2 HERE}

As stated previously, CRM solutions can be categorized as being related to either operational, analytical, collaborative or strategic CRM solution types. In order to have a successful CRM implementation, therefore, the correct solution type should be used to implement key value characteristics. Since characteristics within the summarized themes relate to different CRM types, it appears inappropriate to group characteristics together as it risks critical characteristics being either ignored or wrongly implemented within the final solution. In addition to the grouping of characteristics, Cheng et al. (2005) was inconsistent the value characteristics that were included. For example, within the Data Management / knowledge management theme they neglect to include a very important characteristic.

Although the grouping of characteristics supports the reader in understanding the 'theme' of change to which CRM will add value, the summarising of value characteristics makes explicit implementation more confusing for implementers. Accordingly, we propose a more appropriate framework that explicitly considers each of the 17 defined CRM value characteristics, which allows the implementation approach for each to be considered.

\subsection{New Framework for Implementation of CRM in Nursing Homes}

An adapted framework (see figure 3 ) is presented in this section, to better reflect the results of Cheng et al. (2005), reduce the chance of issues being forgotten, and provide a more holistic and implementation focused. Rather than grouping characteristics together using summary theme headings, as in Figure 2, each individual characteristic is listed separately. As well as avoiding overt summary, this avoids inconsistent classification. By listing each individual characteristic, we not only ensure that consistency in the way that characteristics are 
represented, we are able to produce an efficient implementation plan for CRM; allowing the potential for each value characteristic to be linked to an CRM solution type.

To support practical implementation of CRM, each value characteristic was assigned at least one CRM solution tag (i.e. (O)perational, (C)ollaborative, (S)trategic, and/or (A)nalytical); which in our opinion best represented the type of CRM solution that best meets the requirement defined by the specific value characteristic. Wang (2012) appraised the implementation of customer relationship management (CRM) in 30 hospital-based nursing homes and 108 privately run nursing homes in Taiwan. Results show that hospital and private nursing homes place important on different CRM activities, and have a very different focus when building a relationship with patients. Hospital-based nursing homes place emphasis on understanding resident needs; in order to ensure effective provision of care services. Privately run nursing homes place focus on technology-based CRM when developing relationship with residents. Although it is appropriate that management focus on different customer develop areas, it highlights the differences in CRM implementation strategy, even within the same domain area. By identifying characteristics that are of greatest important to the specific nursing home, CRM implementers can use figure 4 to consider what practical CRM solution may best meet defined value characteristic criteria.

\section{FIGURE 3 HERE}

\section{FIGURE 4 HERE}

Consideration of figure 4 also supports CRM implementers in managing the output expectation of care home staff, management and residents. It should be clear that implementation, for example, of data analytics (i.e. analytical CRM) will only support value characteristics D2, D3, D4, D5 and Care 1. Although analytics may support other value characteristics, additional CRM implementation may be require; which may add additional investment, change duration and risk.

\section{Conclusion}

Cheng et al. (2005) proposed a CRM framework for use within nursing homes, which consisted of three sections, i.e. case management, data management and care management. In each section, it is vital that the appropriate information is captured, to support the 
development of an appropriate CRM database structure; which ultimately allows service provision. This framework, however, provides limited advice concerning how value characteristics can be strategically achieved though CRM implementation.

The main contribution of this work is the provision of an adapted implementation framework that better reflects the data gathered by Cheng et al. (2005). By including all 17 value-characteristics, we are able to ensure consideration during CRM implementation planning. Moreover, by considering and linking value characteristics to CRM solution types, we support specific care homes in assessing what CRM solutions would provide most value.

Practically it is clear that a 'one solution meets all characteristics' approach to CRM implementation within nursing homes is inappropriate. The framework, however, supports those implementing CRM within nursing homes to consider: i) which of the 17 factors are most feasible / relevant to adding immediate value; and ii) what value can be gained by considering specific implementation of key solution types. We hope that this information will support implementers in aligning value gains to business needs, and therefore managing project and customer expectations.

\section{References}

Altmann, R. (2011). Dilnot shows that he cares, and we can afford to. URL: http://www.ft.com/cms/s/2/d5fb93d8-a8c8-11e0-b877-00144feabdc0.html\#axzz1Rz7QLMSR. [12th July 2011]

Baran, R; Galka, R and Strunk, D. (2008). Principles of Customer Relationship Management. Mason, $\mathrm{OH}$ : Thomson South-Western

Barnes, J. (2001). Secrets of Customer Relationship Management. New York: McGraw-Hill

Bathurst, B. (2011). The Secret Life of Libraries. URL: http://www.guardian.co.uk/books/2011/may/01/the-secret-life-of-libraries?INTCMP=SRCH. [3rd May 2011]

Bender, S and Fish, A. (2000). The transfer of knowledge and the retention of expertise: the continuing need for global assignments. Journal of Knowledge Management. 4(2), 125-137

Benz, G. and Paddison, N. (2004). Developing patient-based marketing strategies. Healthcare Executive. 19(5), 40-42

Berglund, A. L. (2007). Satisfaction with caring and lining conditions in nursing homes: Vies of elderly persons, next of kin and staff members. International Journal of Nursing Practice, 13, 46-51

Bose, R. (2003). Knowledge management enabled healthcare management systems: capabilities, infrastructure and decision support. 24(1), 59-71 
Bohling, T., Bowman, D., LaValle, S., Mittal, V., Narayanda, D., Ramani, G., \& Varadarajan, R. (2006). CRM implementation: Effectiveness issues and insights. Journal of Service Research, 9, 184-194

Buttle, F. (2004). Customer Relationship Management: Concepts and Tools. Oxford: Elsevier Buttle, F. (2009). Customer Relationship Management: Concepts and Technologies. Oxford: Butterworth-Heinemann Publications

Campbell, A. (2003). Creating customer knowledge competence: managing customer relationship management programs strategically. Industrial Marketing Management. 32, 375383

Carlucci, D; Marr, B and Schiuma, G. (2004). The knowledge value chain: how intellectual capital impacts on business performance. International Journal of Technology Management. 27(6/7), 575-590

Chahal, H. (2010). Two component customer relationship management model for healthcare services. Managing Service Quality, 20(4), 343-365.

Cheng, B. W., Lin, S. and Liu, J. C. (1998) Use quality function deployment to enhance the overall service quality of outpatient department of the hospital. Proceedings of National Science Council: Humanities \& Social Science, 8(3), 479-493

Cheng, B., Chang, C and Liu, I. (2005). Establishing Customer Relationship Management Framework in Nursing Homes. Total Quality Management. 16(5), pp. 607-629

Cook, I. G., Halsall, J. (2012) Introduction: An Aging World, in (Eds) Powell, J., Chen, S. Aging in Comparative Perspective, International Perspectives on Aging, Springer, 1-6, Doi: 10.1007/978-1-4614-1978-5_1

Dahlgaard, J.J., Pettersen, J., \& Dahlgaard-Park, S.M. (2011). Quality and lean healthcare: A system for assessing and improving the health of healthcare organizations. Total Quality Management \& Business Excellence, 22(6), 673-689.

Dahlgaard-Park, S.M., \& Dahlgaard, J.J. (2010). Organizational learnability and innovability: A system for assessing, diagnosing and improving innovations. International Journal of Quality and Service Sciences, 2(2), 153-174.

Galbreath, J. and Rogers, T. (1999). Customer relationship leadership: A leadership and motivation model for the twenty-first century business. The TQM Magazine. 11(3), pp. 161-71

Glaser, J., \& Foley, T. (2008). The future of healthcare IT. Healthcare Financial Management, 62(11), 82-88.

Gummesson, E. (2002). Total relationship marketing.2nd Edition. Oxford: ButterworthHeinemann/Chartered Institute of Marketing

Hancock, R; Comas-Herrera, A; Wittenburg, R and Pickard, L. (2003). Who Will Pay For Long-Term Care In The UK? Projections Linking Macro- And Micro-Simulation Models. Fiscal Studies. 24(4), pp. 387-426

Johnson, B and Nunes. (2003). Let's talk: applying the art of conversation to customer 
contact, in J.G. Freeland (Ed.), The Ultimate CRM Handbook. New York: McGraw-Hill

Lin, Y. and Su, H. (2003). Strategic analysis of Customer Relationship Management - a field study on hotel enterprises. Total Quality Management, 14(6), 715-731.

MacStravic, S. (2000). The downside of patient empowerment: while consumers and managed care alike applaud the trend toward empowering patients, this shift has placed new and sometimes overwhelming burdens on consumers. Health Forum Journal. January/February, 30-31

Massey, A., Montaoya-Weiss, M., \& Holcom, K. (2001). Re-engineering the customer relationship: Leveraging knowledge assets at IBM. Decision Support Systems, 32(2),155170.

METAGroup (2001). Integration: Critical issues for implementing of CRM solutions. Stamford, CT: META Group Inc

Michie, S; Miles, J and Weinman, J. (2003). Patient-centredness in chronic illness: what is it and does it matter? Patient Education and Counseling. 51, 197-206

Nykamp, M. (2001). The customer differential: the complete guide to implementing customer relationship management. New York :AMACOM

ONS (2012). Population Ageing in the United Kigdom its constituent countires and the European Union. Release $2^{\text {nd }}$ of March 2012. Accessed $23^{\text {rd }}$ July 2012 from http://www.ons.gov.uk/ons/dcp171776_258607.pdf

Oinas-Kukkonen, H., Raisanen, T., \& Hummastenniemi, N. (2008). Patient relationship manage- ment: An overview and study of a follow-up system. Journal of Healthcare Information Management, 22(3), 24-29.

Ouschan, R, Sweeney, J and Johnson, L. (2006). Customer empowerment and relationship outcomes in healthcare consultations. European Journal of Marketing. 40(9/10), pp. 10681086

Payne, A. (2006). Handbook of CRM: Achieving Excellence in Customer Management. Oxford: Butterworth-Heinemann Publications.

Payne, A.and Frow, P. (2005). A strategic framework for customer relationship management. Journal of Marketing. 69(4), pp. 167-76

Peppers, D and Rogers, M. (1993). The One to One Future, Double Day, Division of Bantam, Double Day. New York: Dell Publishing Group

Plakoyiannaki, E. and Tzokas, N. (2002). Customer relationship management: A capabilities portfolio perspective. Journal of Database Marketing. 9(3), 228-237

Reimann, M., Schilke, O. \& Thomas, J.S. (2010). Customer relationship management and firm performance: The mediating role of business strategy. Journal of the Academy of Marketing Science, 38(3), 326-346.

Rigby, D; Reichheld, F and Schefter, P. (2002). Avoid the four perils of CRM. Harvard Business Review. 80(2), pp. 101-109

Riyad Eid (2007): Towards a Successful CRM Implementation in Banks: An Integrated Model, 
The Service Industries Journal, 27:8, 1021-1039

Schniederjans, M.J, Cao, Q. \& Gu, V. C. (2011). An operations management perspective on adopting customer-relations management (CRM) software, International Journal of Production Research, DOI:10.1080/00207543.2011.613865

Shoemaker, M. (2001). A framework for examining IT-enabled market relationships. Journal of Personal Selling and Sales Management. 21(2), pp. 177-185

Storbacka, K and Lehtinen, J. (2001). Customer Relationship Management. Creating Competitive Advantage through Win-Win Relationship Strategies. New York: McGraw-Hill

Swift, R. (2001). Accelerating customer relationships: Using CRM and relationship technologies. Englewood Cliffs, NJ: Prentice-Hall

Tanner Jr., J; Ahearne, M; Leigh, T ; Mason, C and Moncrief, W (2005). CRM Sales intensive organizations: A review and future directions. Journal of Personal Selling \& Sales Management. 25(2), pp. 169-180

Vargo, S.L. \& Lusch, R.F. (2008). Service-dominant logic: Continuing the evolution. Journal of Academic Marketing Science, 36(1), 1-10.

Vernarec, E. (1999). Health care power shifts to the people. Business and Health. 17(6), 8-13

Wang M. (2012). An evaluation of customer relationship management in hospital-based and privately run nursing homes in Taiwan, Total Quality Management \& Business Excellence, DOI:10.1080/14783363.2011.637783 


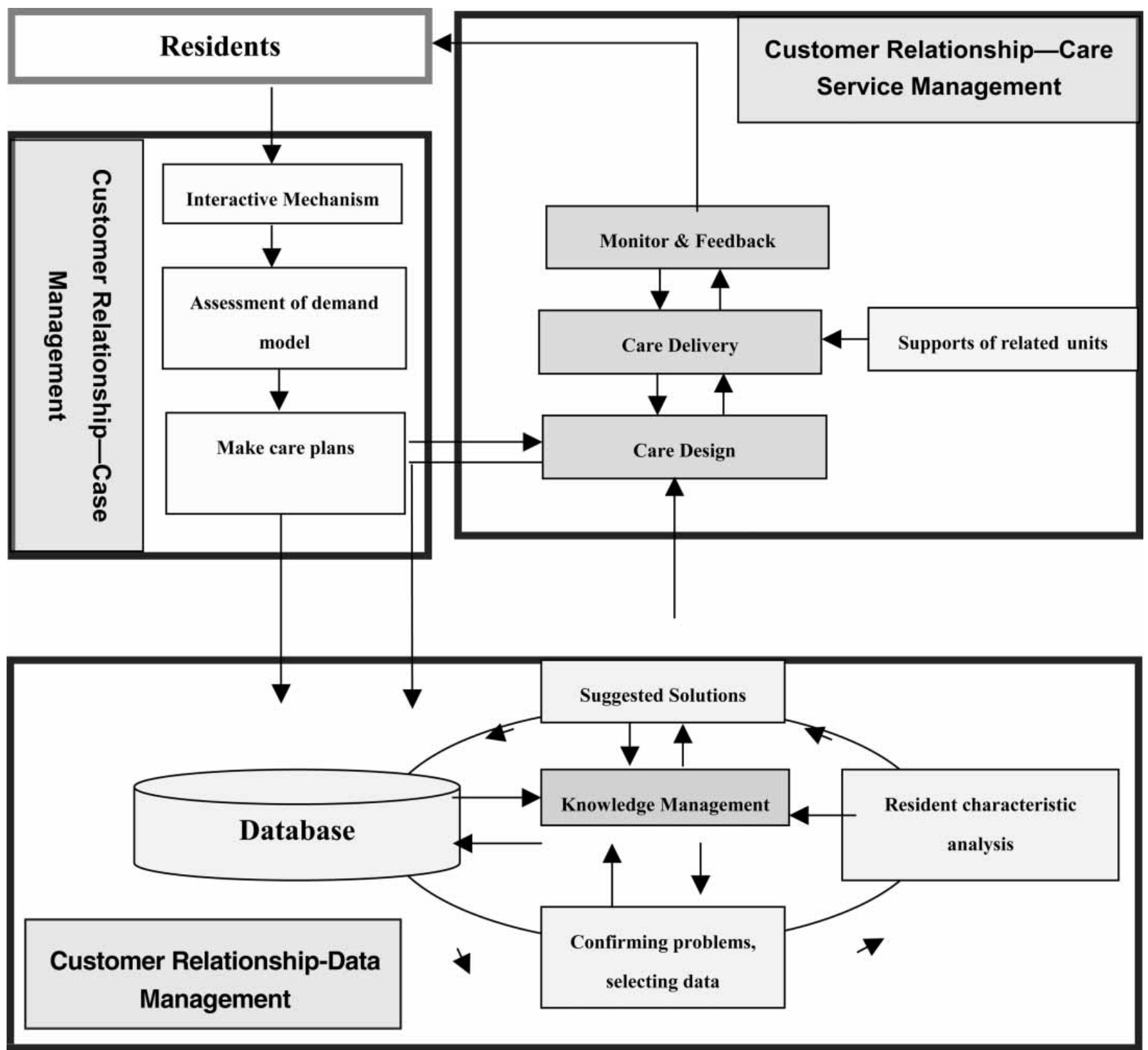

Figure 1: CRM Framework for Care Institutions (adopted from Cheng et al., 2005) 


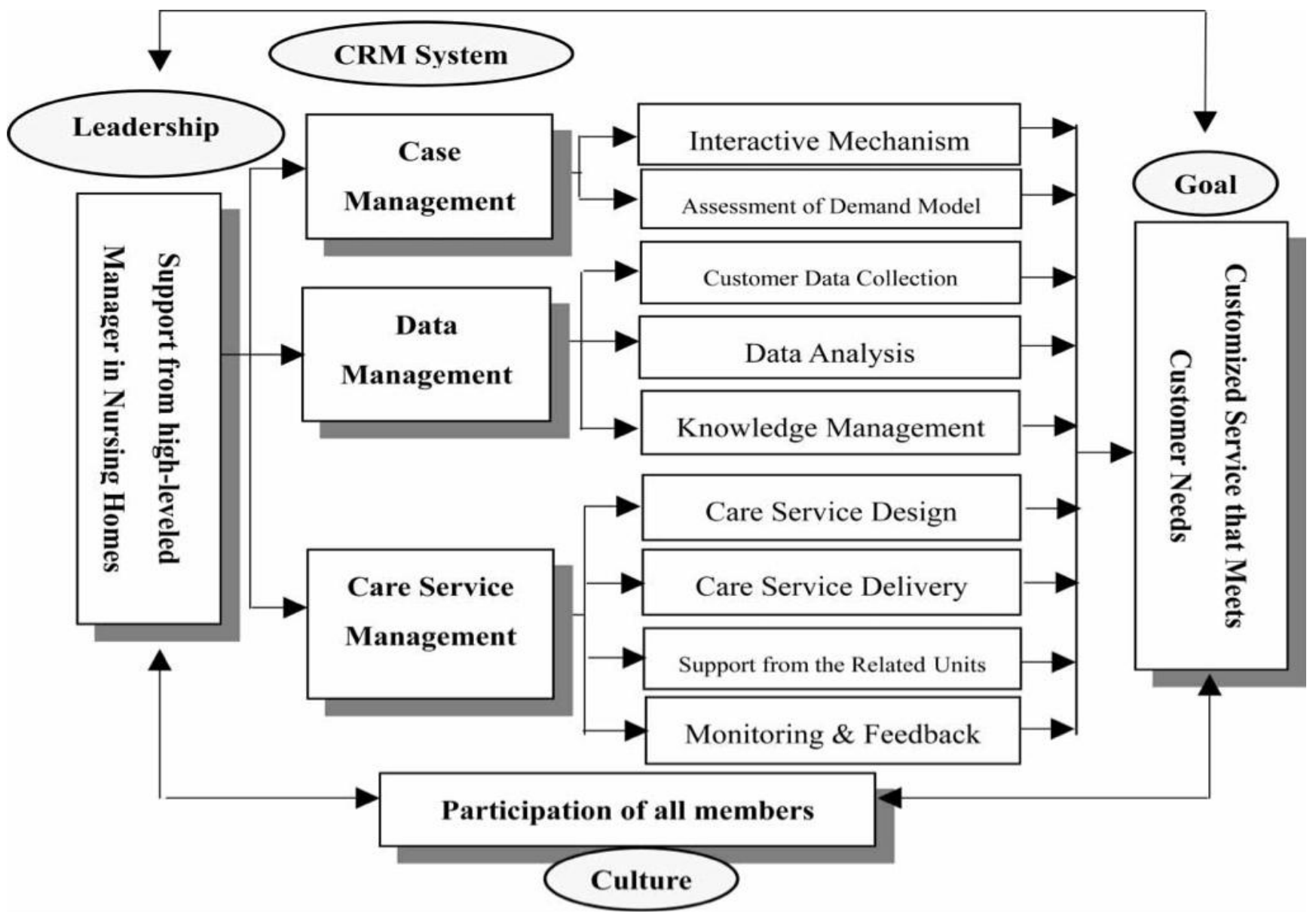

Figure 2. Overall Framework of introducing CRM in Nursing Homes (Cheng et al., 2005). 


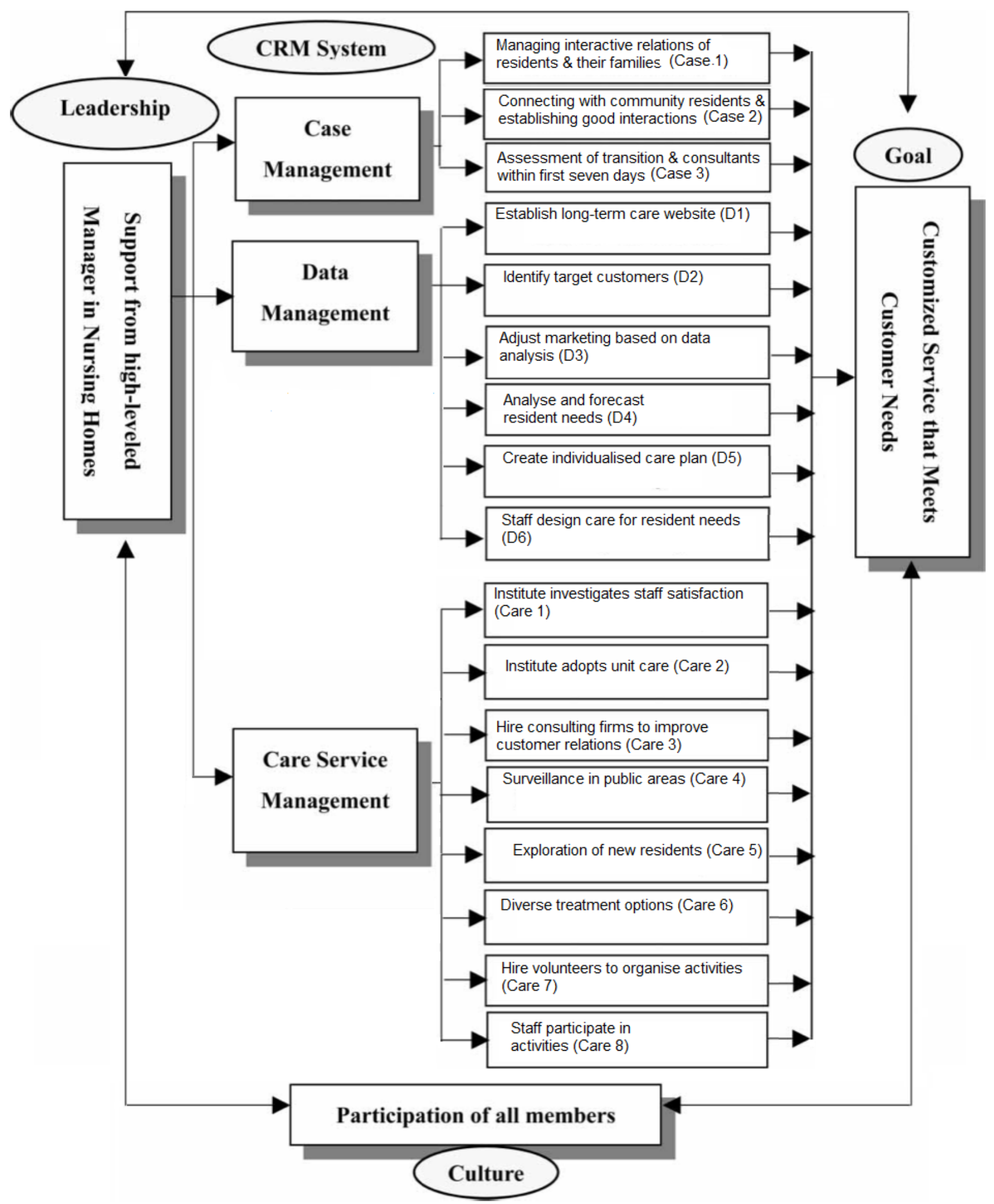

Figure 3. Adapted CRM Value Framework of introducing CRM in Nursing Homes 


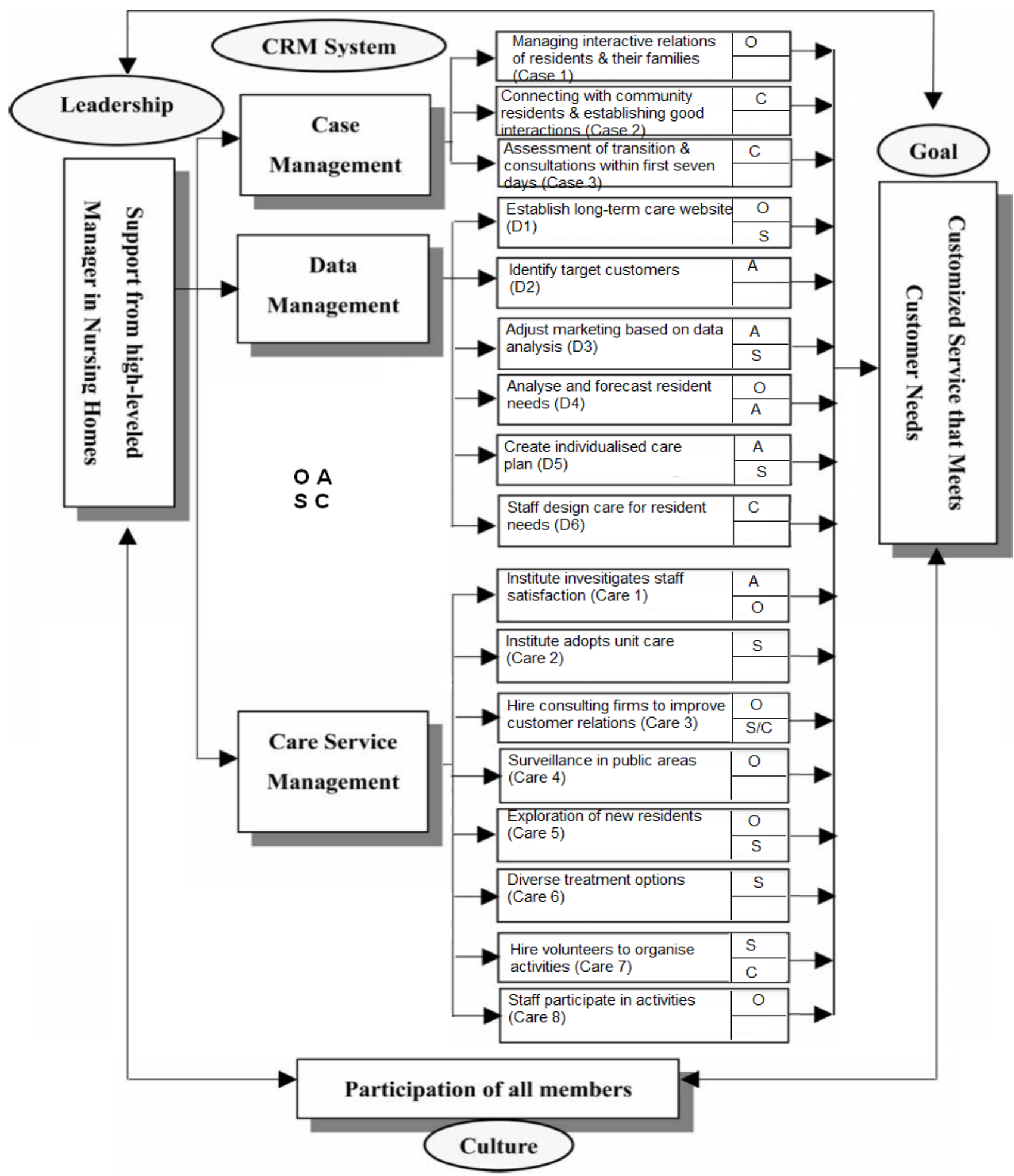

Figure 4. "Strategic" Framework for CRM implementation in Nursing Homes.

$\mathrm{S}=$ Strategic $\mathrm{CRM} ; \mathrm{O}=$ Operational $\mathrm{CRM} ; \mathrm{C}=$ Collaborative $\mathrm{CRM} ; \mathrm{A}=$ Analytical $\mathrm{CRM}$ 